\title{
IMPLICAÇÕES E CONQUISTAS DA ATUAÇÃO DO INTÉRPRETE DE LÍNGUA DE SINAIS NO ENSINO SUPERIOR
}

\section{Vanessa Regina de Oliveira Martins}

\begin{abstract}
RESUMO
A profissão do intérprete educacional tem ganhado espaço dentro da sala de aula. Salientamos que a notória presença e a maior visibilidade, atualmente, do intérprete de língua de sinais, é caracterizada no ensino superior. Isso em cumprimento da legislação que garante ao educando, com necessidades especiais, as mudanças necessárias para o atendimento e as adaptações pertinentes ao seu pleno acesso dentro da instituição de ensino. Nesse estudo observaremos a atuação do intérprete no ensino superior e as mudanças corporativas referentes à recepção e enquadramento deste novo profissional da educação.
\end{abstract}

PALAVRAS-CHAVE

Intérprete de língua de sinais; Ensino superior; Inclusão; Surdez.

\section{IMPLICATIONS AND CONQUESTS OF THE PERFORMANCE OF THE INTERPRETER OF LANGUAGE OF SIGNALS IN SUPERIOR EDUCATION}

\begin{abstract}
The profession as an educational interpreter has gained more and more ground in the classroom. It is important to emphasize that the greater current presence and visibility of the interpreter are specially noticed at the university-level education. That is due to the Brazilian legislation, which guarantees the necessary changes and adaptations for pupils with special needs, so that he or she can have full access to the educational facilities. This study aims to show the work of the interpreter in higher education and the corporate changes concerning the reception and the adjustments of this new professional in education.
\end{abstract}

\section{KEYWORDS}

Sign language interpreter; University-level education; Deafness 


\section{ARTIGO \\ Processos Tradutórios, Línguas de Sinais e Educação \\ Grupo de Estudos e Subjetividade}

\section{INTRODUÇÃO}

Para entender e discutir a situação educacional atual de surdos incluídos na universidade com a presença do intérprete de língua de sinais é necessário, antes, compreender o processo histórico de luta da comunidade surda dentro do contexto educacional. A história da educação de surdos nos aponta três abordagens filosóficas que são elas: oralismo, comunicação total e bilingüismo. Embora encontremos presentes atualmente pensadores para as três linhas filosóficas, iremos focar neste trabalho, a abordagem educacional bilíngüe ${ }^{1}$ que tem embasamento teórico nas contribuições de autores como: (GOES, 1996; SKLIAR, 1997; SOUZA, 1998; LACERDA, 2000; FERNANDES, 2003).

Neste processo de educação: no qual o surdo é parte ativa e participante do contexto educacional e do projeto pedagógico; torna-se relevante pensar em medidas que incluam o surdo. Baseado na proposta bilíngüe vincula também a concepção do sujeito surdo sinalizado como produtor de uma realidade outra. Este advém de uma minoria lingüística com múltiplas culturas que refletirá no ensino. Espera-se, ainda dentro da concepção bilíngüe, que o surdo apreenda o conhecimento através de sua língua primeira (L1) vista como língua “natural” (FERNANDES, 2003, p.17). Neste contexto o intérprete torna-se parte ativa do processo pedagógico. A proposta bilíngüe:

é aquela que acima de tudo estabelece que o trabalho escolar deve ser feito em duas
línguas, com privilégios diferentes: A Língua de Sinais como primeira língua (L1) e
a língua da comunidade ouvinte local como segunda língua (L2) (SÀ, 1999, p.135).

Sob a ótica desta abordagem, enfocaremos, neste trabalho, as salas de ensino superior inclusiva com a presença do intérprete de língua de sinais, que utiliza a Libras como mediadora entre aluno e os saberes sistematizados. Ressaltamos que pela diferença estrutural da língua de sinais e da língua portuguesa, não cabe o pensamento futurista e um tanto quanto utópico de que dentro da universidade, os diversos professores irão aprender a Libras e transmitir os conhecimentos pela mesma, sinalizando e verbalizando concomitantemente. Essa razão evidencia e justifica a necessidade da atuação do intérprete como mediador educacional.

\footnotetext{
${ }^{1}$ A abordagem bilíngüe traz a concepção de surdo como usuário de uma língua distinta da majoritária do país. A língua de sinais brasileira L1 para surdos residentes no Brasil e L2 o português podendo ser na modalidade escrita ou oral.
} 


\section{ARTIGO \\ Processos Tradutórios, Línguas de Sinais e Educação Grupo de Estudos e Subjetividade}

Dados importantes nos informam que há atualmente cerca de 300 estudantes surdos, de acordo com a Profa. Marlene Gotti ${ }^{2}$, assessora da Secretaria de Educação Especial (Seesp/MEC), matriculados no ensino superior do Brasil. Este dado nos aponta a necessidade e urgência de medidas que incluam e tragam os surdos à academia, pois quantitativamente temos uma gama de pessoas surdas à margem do sistema educacional de ensino. Isto acontece, segundo a assessora profa Marlene, devido à evasão de alunos surdos da escola regular na medida em que o grau de instrução aumenta.

Recentemente, com a lei no-10.436 de 24 de abril de 2002, sancionada pelo expresidente Fernando Henrique Cardoso, que reconhece oficialmente a Língua de Sinais como língua utilizada pela comunidade surda, vemos aumentar o número de alunos surdos matriculados no ensino superior. A legislação trouxe algumas mudanças dentro das universidades; o crescente aumento na contratação do intérprete de língua de sinais é um dos exemplos. Isto ocorreu também pela determinação e cobrança dos surdos por seus direitos enquanto falantes de uma língua diferente da usada majoritariamente no país. A mesma lei referida acima, salienta e concede o direito aos surdos de uma educação inclusiva plena, alertando que:

\footnotetext{
Art. $8^{\circ}$ As instituições de ensino da educação básica e superior, públicas e privadas, deverão garantir às pessoas surdas acessibilidade à comunicação nos processos seletivos, nas atividades e nos conteúdos curriculares desenvolvidos em todos os níveis, etapas e modalidades de educação (LEI no 10.436/02).
}

Percebemos a partir desta conquista legal diversos benefícios à comunidade surda que tem atualmente uma maior visibilidade quanto ao uso da língua de sinais principalmente nas instituições de ensino superior.

Com esta medida o sistema de ensino deve responsabilizar-se pela interação professor e aluno surdo; ao receber o surdo deve respeitar a condição da diferença lingüística deste aluno e oferecer subsídios metodológicos específicos para seu real desenvolvimento dentro da instituição. Esta lei ainda contempla e assegura a utilização do apoio do intérprete de Libras em casos de surdos sinalizados que solicitem o trabalho do mesmo.

Objetiva-se, neste trabalho, observar a relação intérprete-surdo no contexto educativo. Por lidar com o conhecimento e o saber sistematizado, há uma longa discussão

\footnotetext{
${ }^{2}$ Entrevista publicada no site www.sentidos.com.br, no dia 1/02/2005, referente a lei da libras. Repórter: Susan Faria.
} 


\section{ARTIGO \\ Processos Tradutórios, Línguas de Sinais e Educação Grupo de Estudos e Subjetividade}

acadêmica sobre a nomenclatura do interprete educacional: "professor-intérprete”; “intérprete educacional”; “tradutor em sala de aula”. (Lacerda, 2002; Rosa, 2005). Neste trabalho usarei a nomenclatura intérprete educacional.

Partindo do pressuposto definido por Rosa (2005), o intérprete de língua de sinais é visível e utiliza a língua de sinais na modalidade visual-gestual; assim o ato interpretativo só acontece com a presença física deste profissional. Segundo a autora "o intérprete é aquele que faz uma tradução ao vivo... representando como teatro” (ROSA, 2005, p.90).

O prefixo INTER, na palavra intérprete, significa o que está entre uma língua e outra, pondo essas línguas em relação, criando uma afinidade entre elas. Os gestos da intérprete constroem o sentido do que digo; e ela depende disso para sua construção, assim como dependo de seus gestos para que esta fala sobreviva. (VERAS ${ }^{4}, 2002$ apud ROSA 2005, p.90).

O intérprete de língua de sinais, por ser um profissional da tradução, fica constantemente mediando as inter-relações que envolvam a comunicação; posicioná-se exatamente entre uma língua e outra, transportando os discursos e trazendo compreensão ao desconhecido.

No caso do intérprete educacional que atua na sala de aula, alertamos que a interpretação não é consecutiva, por não acontecer em tempo real. Neste caso é possível que o aluno questione dialogando com o intérprete entre uma explicação e outra e este procurará sanar as dúvidas antes mesmo de recorrer ao professor (caso ele sinta-se seguro para tal iniciativa). Por isso, o ato interpretativo na sala de aula requer que o intérprete compreenda o estudo explanado para posteriormente auxiliar o aluno. Todo o processo de ensino e aprendizagem passa pelo intérprete educacional; que tem uma visão holística de todo o processo de ensino e aprendizagem do aluno surdo.

O professor torna-se parceiro neste processo, trazendo os conteúdos e mediando ao intérprete que, nesta trama, torna-se "mediador do mediador”, (Martins, 2004, p.37). Fica também sob a responsabilidade do intérprete o oferecimento de subsídios que promovam a interação entre aluno e professor e supostas alterações metodológicas; sempre em estreita parceria com os professores.

\footnotetext{
${ }^{3}$ FENEIS.Regulamentação da Libras: http://www.feneis.com.br/regulamentação.shtml. Acesso em: 11 de maio de 2006.

${ }^{4}$ A autora discursou sua fala em palestra realizada no I Seminário de Intérprete de Língua de Sinais: O intérprete na sala de aula a prática da diferença, em Campinas: Salão Vermelho da Prefeitura Municipal de Campinas,
} 2002. 
Assim, a presença deste profissional traz uma proposta que ameniza o problema na interação comunicativa entre professor e aluno surdo, pois ele é uma ponte entre: professor, conhecimento e aluno surdo; e sem dúvida, este novo profissional tem atraído o surdo à universidade, já que propicia o ensino do conteúdo pela língua de sinais facilitando a aprendizagem.

A seguir um esquema representando a abrangência da mediação do intérprete educacional dentro da sala de aula:

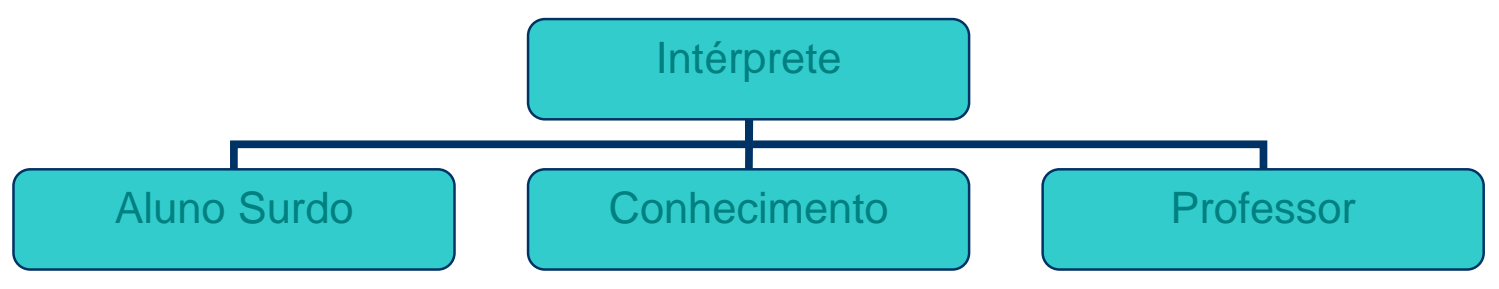

Trago, ainda, uma reflexão e análise da minha prática dentro de duas universidades distintas A e B, onde atuei como intérprete de língua de sinais. A busca pela identificação dos diferentes aspectos referentes ao meu trabalho como intérprete de língua de sinais nestas universidades, nas quais a atuação é direta com alunos surdos, tem a pretensão de mostrar as diferentes concepções que ambas assumem frente ao meu trabalho exercido em relação à pessoa surda.

\section{ANÁLISE EMPÍRICA NO CAMPO DE ATUAÇÃo}

O estudo contribuiu para a análise do relacionamento estabelecido entre alunos ouvintes/surdos, intérprete, professor e instituição, abrindo caminho para outras possibilidades de pesquisas.

A partir da observação empírica em sala de aula, iniciada pela minha primeira experiência como intérprete no ensino superior em janeiro de 2004, coletei alguns dados em entrevistas que serviram para reflexão em minha pesquisa de trabalho de conclusão de curso em pedagogia: formação de professores para a educação especial, realizada na puccamp em 2004. Destas propostas surgiram novos questionamentos aumentando ainda mais as possibilidades de reflexão e comparação dos avanços na área com as experiências que adquiri em outras instituições de ensino superior. 
Pretendo trazer alguns dados especificamente de duas instituições de ensino superior, para vislumbrarmos as semelhanças, conquistas e status que a profissão de intérprete de língua de sinais têm conquistado na história, em decorrência da legislação e da crescente preocupação com as diferenças evidenciadas na inclusão.

Observando o gráfico abaixo percebemos distinções iniciais nas experiências e mudanças importantes na concepção coorporativa do trabalho do intérprete dentro da instituição de ensino, ambas particulares.

\begin{tabular}{|c|c|}
\hline $\begin{array}{l}\text { Instituição A } \\
\text { Curso: Pedagogia }\end{array}$ & $\begin{array}{c}\text { Instituição B } \\
\text { Curso: Arquitetura e Urbanismo }\end{array}$ \\
\hline $\begin{array}{l}\text { * Bolsista } \\
\text { * Comínio do conteúdo } \\
\text { alunos e professores } \\
\text { * Dificuldade na abertura para } \\
\text { discussões e partilhas. } \\
\text { * Aluna Surda usuária da Libras } \\
\text { sem fluência. }\end{array}$ & $\begin{array}{l}\text { Funcionária } \\
\text { * Não domínio do conteúdo } \\
\text { voltado ao acompanhamento } \\
\text { pedagógico } \\
\text { * Abertura para trocas e partilhas } \\
\text { com professores. } \\
\text { * Aluno Surdo usuário e fluente } \\
\text { na Libras. }\end{array}$ \\
\hline
\end{tabular}

Atuei no curso de pedagogia, na instituição A, como bolsista num período de seis meses e no curso de arquitetura, atualmente na instituição $B$, atuo como intérprete educacional. O trabalho, nesta última instituição, foi iniciado desde o ingresso do aluno na universidade, que soma aproximadamente um ano e meio.

Vale salientar o advento dos surdos sinalizados no ensino superior, ilustrado nas duas experiências citadas; antes majoritariamente marcado por surdos oralizados. A aluna da instituição A embora pouca fluência na libras, requerendo que durante as aulas explicassem os sinais utilizados, também não exercia boa oralidade. Já o aluno da instituição $B$, faz uso apenas da Libras e curiosamente, formou-se durante todo os outros níveis escolares em escolas especiais com uso da língua de sinais como mediadora na aquisição dos conteúdos. 
Avalio como fator de extrema relevância no processo de descoberta da atuação como intérprete educacional: a necessidade do aprofundamento teórico na área de estudo do educando surdo; evidenciado, por mim, no curso de arquitetura, já que o fato de ter me formado em pedagogia facilitou a atuação neste curso em outra instituição.

A falta de conhecimento específico em cada curso marca o pouco/nenhum domínio do conteúdo explanado. A princípio este é o ponto principal da dificulta da atuação do intérprete acadêmico. A lacuna só ameniza na medida em que o intérprete vai se familiarizando com a linguagem utilizada em cada situação e faz parcerias com o professor. Cabe ao profissional um compromisso com a educação do aluno em questão e pela sistematização do estudo, mesmo em horários extra-sala, apropriar-se do conhecimento que a priore é desconhecido.

Atualmente sou contratada pela instituição de ensino $B$, que diz entender o trabalho realizado como um apoio pedagógico; contradizendo-se, portanto, ao incluir os intérpretes na área administrativa e não à pedagógica. Esta instituição tem em seu quadro de funcionários quatro intérpretes educacionais contratados, atendendo em cursos distintos: arquitetura e urbanismo, administração e medicina veterinária.

Poucos conhecem o trabalho dentro da instituição B e por estar separado da área pedagógica dificulta o posicionamento e a melhor relação entre intérprete e professores. Notase que o fato de estarmos respondendo pela acessibilidade do aluno e sermos considerados especialistas neste segmento, dentro da empresa, temos conquistado pouco a pouco, espaço para realização de algumas mudanças metodológicas, pensando na melhoria e adaptação do surdo na universidade.

A falta de conhecimento deste profissional atrapalha durante a contratação, uma vez que a pessoa a quem respondemos nada conhece desta prática, apenas o que dizem o senso comum. Não disponibilizam de critérios para contratação, senão que o candidato comprove alguma experiência com surdos e com a Libras. Atualmente com a ampliação da profissão e a gama de pessoas que se “dizem intérpretes”, as universidades têm exigido nível superior e comprovação de cursos de Libras.

Como sabemos “os intérpretes formam-se através da prática” com a comunidade surda, (Rosa, 2005, p.114), poucos que iniciam trabalhos em escolas, têm de fato experiências na educação, principalmente com as questões da aprendizagem, tão importantes dentro da sala de aula. 


\section{ARTIGO \\ Processos Tradutórios, Línguas de Sinais e Educação \\ Grupo de Estudos e Subjetividade}

Ainda encontramos muitos intérpretes atuando dentro de instituições de ensino superior sem nenhuma experiência educacional e nenhuma habilitação em um curso de graduação, e o que é pior sem fluência na Libras. Necessidades estas básicas para a atuação em sala de aula. Isto ocorre porque a maioria dos intérpretes inicia seu contato com a Libras dentro de movimentos religiosos e acompanhamentos assistenciais generalizados.

A falta de preparo e formação específica a que nos deparamos atualmente, além de prejudicar na formação do aluno surdo, dificulta na escolha (contratação) dos intérpretes educacionais e acarreta no descrédito da profissão: prejudicando os profissionais que tem investido na qualificação dentro desta área.

Contudo vale considerar o percurso e as mudanças que tivemos, nesta experiência citada; da concepção de caráter assistencialista para o reconhecimento da profissão pela prática dentro da universidade. Sem dúvida, estes eventos têm caracterizado pontos positivos para o processo de reconhecimento legal desta profissão.

\section{CONSIDERAÇÕES FINAIS}

Reconheço que avanços aconteceram e que estas experiências amadureceram as inter-relações melhorando minha práxis. Hoje compreendo que o trabalho do intérprete na sala de aula difere dos demais campos de atuação do intérprete generalista ${ }^{5}$ por ser um trabalho pedagógico que requer um procedimento sistematizado de ensino e um compartilhar direto com os professores.

Esta minha experiência, que nada tem a pretensão de esgotar o tema, mas intrigar o desenvolvimento de novas pesquisas, tem por objetivo trazer a concepção de que a profissão do intérprete educacional, dentro da sala de aula no ensino superior não se limita ao ato tradutório concebido pelo senso comum, ou seja, um mero transportar de conteúdos estáticos de uma língua para outra, mas uma atuação pedagógica uma vez que lidamos com o conhecimento e com as questões de aprendizagem.

É o intérprete que percebe a dificuldade e tenta encontrar caminhos e métodos que facilitem a aquisição do conhecimento. Assim, faz-se necessário o envolvimento deste profissional com as questões didático-pedagógicas dentro deste contexto.

\footnotetext{
${ }^{5}$ Este interprete atua em diversos campos sociais e na maioria dos atendimentos faz uso da interpretação simultânea. Acompanha em: hospitais, fóruns, audiências entre outras localidades que a comunicação entre surdos e ouvintes é necessária. 
Sem dúvida este tema abrange diversos fatores a serem pensados requerendo, portanto, um estudo aprofundado nesta área e uma formação específica para estes novos profissionais da educação que urgentemente estão sendo convocados para adentrar na sala de aula e atuar muitas vezes sem o respaldo teórico necessário. Precisamos de aprofundamento teórico para melhor conhecer e definir, com clareza, a atuação e papel deste profissional que adentrou no campo educacional e tem construído a sua formação por meio da prática.

\section{REFERÊNCIAS}

FERNANDES, E. Linguagem e Surdez. Porto Alegre: Artmed, 2003.

GOES, M.C.R. Linguagem, surdez e educação. Campinas: Autores Associados, 1996.

LACERDA, C. B. F. O intérprete educacional de língua de sinais no ensino fundamental: refletindo sobre limites e possibilidades. In: LODI, A C. B., at. (Org). Letramento e Minorias. Porto Alegre: Mediação, 2002.

MARTINS, V. de O. Intérprete ou professor: o papel do intérprete de língua de sinais na educação inclusiva de alunos surdos. 2004. Trabalho de Conclusão de Curso de Pedagogia em Educação Especial - Faculdade de Educação da Pontifícia Universidade Católica de Campinas. Campinas, 2004.

ROSA, A. S. Entre a visibilidade da tradução da língua de sinais e a invisibilidade da tarefa do intérprete. Dissertação de Mestrado - Faculdade de Educação na Universidade Estadual de Campinas, SP, 2005.

SÁ, Nídea R. L. de. Educação de Surdos: A Caminho do Bilingüismo. Niterói: EDUFF, 1999.

SKLIAR, C. (Org) Educação e exclusão - abordagem socioantropológica em educação especial. Porto Alegre: Mediação, 1997.

SOUZA, R.M. de. Que palavra que te falta? São Paulo, 1998.

Por uma escola para todos. Para quais todos? In: COLÓQUIO DO LEPSI, 5, 2004, São Paulo. Anais... São Paulo: Faculdade de Educação da USP, 2004. (palestra) 

estudante de pós-graduação em psicopedagogiaAtualize/Curitiba; membro do grupo de estudos surdos (GES)- 